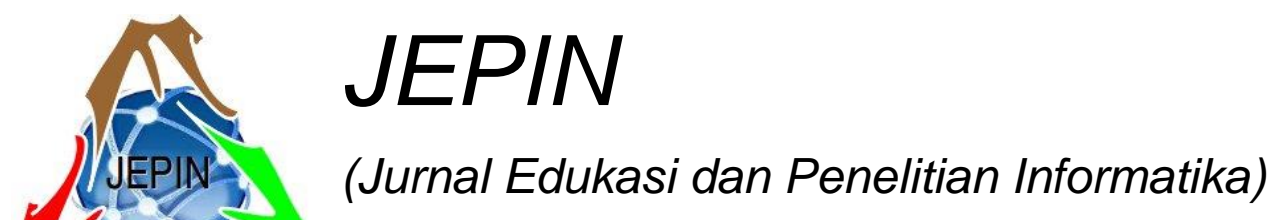

Vol. 7

No. 2

\title{
Analisis Algoritma K-Medoids pada Sistem Klasterisasi Produksi Perikanan Tangkap Kabupaten Aceh Utara
}

\author{
Fajriana $^{\# 1}$ \\ \#Program Studi Teknik Informatika Universitas Malikussaleh \\ Jl. Medan-Banda Aceh, Cot Teungku Nie, Reuleut, Krueng Geukueh,Kab. Aceh Utara-Aceh \\ fajriana@unimal.ac.id
}

\begin{abstract}
Abstrak - Belum adanya sistem pengelolaan data produksi perikanan tangkap di Kabupaten Aceh Utara menyebabkan pemerintah Kabupaten Aceh Utara kesulitan dalam mengklasterisasi data produksi perikanan tangkap. Penelitian ini bertujuan untuk menerapkan algoritma kmedoids dalam sistem klasterisasi data produksi perikanan tangkap berbasis web menjadi tiga klaster. Penelitian ini menggunakan data produksi perikanan tangkap di Kabupaten Aceh Utara tahun 2019-2020 yang diperoleh dari Dinas Kelautan dan Perikanan Kabupaten Aceh Utara. Hasil penelitian dengan 10 kali pengujian menunjukkan bahwa nilai rata-rata iterasi k-medoids sebesar 2,5 dengan jumlah iterasi terbanyak 4 iterasi dan iterasi terkecil senilai 2 iterasi. Hasil cluster data produksi perikanan tangkap dengan jenis tangkapan ikan Albakora masuk kedalam potensi produksi tangkapan klaster sedang. Jenis tangkapan ikan Alu-alu, Tongkol Krai, Tuna Mata Besar, Tuna Sirip Biru Selatan masuk kedalam cluster rendah. Jenis tangkapan ikan Banyar, Bawal Hitam dan Bawal Putih masuk kedalam klaster tinggi. Adapun hasil klaster yang terbentuk dapat membantu pemerintah Kabupaten Aceh Utara dalam mengambil kebijakan untuk menambah nilai produksi tangkapan ikan di Kabupaten Aceh Utara.
\end{abstract}

Kata kunci-Perikanan Tangkap, Clustering, K-Medoids, Aceh Utara

\section{Pendahuluan}

Saat ini teknologi komputerisasi berkembang pesat sehingga sangat banyak teknik dan algoritma baru didalam menyelesaikan suatu permasalahan. Teknologi machine learning atau lebih dikenal dengan pembelajaran mesin mempunyai algoritma yang diklasifikasikan menjadi dua teknik, yaitu supervised learning dan unsupervised learning [1]. Supervised learning ialah teknik machine learning yang biasanya digunakan untuk mengklasifikasikan data yang telah terpola[2]. Ada beberapa algortima supervised learning, seperti K-Nearest Neighbor, Support Vector Machine, Naive Bayes [3]. Unsupervised learning ialah metode machine learning yang bisa diaplikasikan dalam mengklaster objek data yang masih belum terpola. Beberapa contoh algoritma unsupervised learning adalah seperti k-means, k-medoids, fuzzy c-means, Single Linkage, Complete Linkage, Average Linkage [4] [5].

Proses pengelompokan atau klasterisasi data menjadi sebagian kelompok data yang terpisah supaya data yang ada di didalam tiap-tiap kelompok sebagai suatu grup data yang membawa kemiripan yang relatif mirip dinamakan clustering [6][7]. Saat ini pemanfaatan teknologi machine learning dengan teknik clustering sangat penting untuk diimplementasikan dalam berbagai aspek, salah satunya di dalam bidang kelautan dan perikanan.

Data produksi perikanan tangkap di Dinas Kelautan dan Perikanan Aceh Utara, setiap tahun mendapatkan hasil tangkapan hampir ratusan Ton yang terbagi dalam 75 jenis ikan di 8 kecamatan di kabupaten Aceh Utara. Pengelolaan data tersebut saat ini dinilai belum optimal karena belum adanya sebuah system yang dapat mengelompokkan data. Oleh karena itu dibutuhkan proses pengelompokan data dan pembuatan aplikasi berbasis web untuk mengelompokkan data produksi perikanan tangkap menjadi beberapa cluster yaitu rendah, sedang dan tinggi. Data Produksi perikanan tangkap ialah data hasil tangkapan ikan yang dilakukan di perairan laut dan perairan umum baik yang didaratkan di pelabuhan maupun non pelabuhan [8]. Data disajikan menggunakan satuan ton dari tahun 2019-2020.

Pada penelitian ini penulis menerapkan algoritma kmedoids dalam system klasterisasi produksi perikanan tangkap di kabupaten aceh utara berbasis web. K-Medoids adalah suatu algoritma yang dapat diimplementasikan dalam proses clustering yang memakai objek menjadi representasi (medoid) untuk pusat cluster pada setiap kelompok[9]. Penelitian ini dapat memberikan rekomendasi bagi pemerintah kabupaten aceh utara dalam menentukan kebijakan terhadap nilai produksi perikanan tangkap berdasarkan hasil dari klasterisasi objek data, seperti penambahan kapal tangkap terhadap nilai produksi dengan cluster rendah. 


\section{TinjaUAn PUSTAKA}

\section{A. Machine Learnig}

Machine learning ialah jenis dari kecerdasan buatan yang mempersiapkan komputer dengan kapasitas yang dapat belajar dari banyak data, dengan tidak sebagai spesifik perlu menuruti perintah terprogram [9]. Machine learning mempunyai tujuan pokok terhadap ekspansi sebuah aplikasi yang dapat belajar dengan sendirinya agar bisa memberikan keputusan terhadap sesuatu, dengan tidak perlu berulang kali diintruksikan oleh manusia [10] Dengan adanya algoritma tersebut, mesin tentu tidak saja mampu mendapatkan rule atau aturan agar mendapatkan optimalisasi permasalahan dalam suatu pengambilan keputusan, namun juga dapat menyesuaikan dengan transformasi yang terjadi dan dapat juga menelaah sekumpulan objek data yang besar agar bisa menemukan suatu pola tertentu. Algoritma machine learning dikelompokkan menjadi dua teknik yaitu supervised learning dan unsupervised learning. Adapun supervised learning ialah metode machine learning yang biasanya digunakan untuk mengklasifikasikan data yang telah terpola. Unsupervised learning ialah metode machine learning yang biasanya diaplikasikan dalam proses clustering data yang belum terpola.

\section{B. Clustering}

Clustering ialah suatu prosedur dalam memilah data di dalam kumpulan deret data ke dalam sebagian kelompok yang kemiripan datanya terhadap satu kelompok yang nilainya lebih banyak dari kemiripan dengan objek data di dalam kelompok yang lain[11].

Pada prosedur menganalisis cluster, teknik yang dipakai untuk memilah data agar menjadi bagian data yang berlandaskan kemiripan sesuai dengan ketentuan sebelumnya. Jadi dalam menganalisis analisis cluster umumnya bisa dikategorikan dengan:

- Data yang tersedia di dalam suatu cluster mempunyai nilai kemiripan yang besar.

- Data yang tersedia di dalam suatu cluster yang berbeda mempunyai nilai kemiripan yang kecil [12][13].

\section{Algoritma K-Medoids}

Partitioning Around Medoids (PAM) atau K-Medoids ialah suatu algoritma clustering yang hamper sama dengan algoritma K-Means. Yang membedakan diantara kedua teknik atau algoritma ini adalah algoritma $K$-Medoids atau PAM memakai data menjadi representasi atau perwakilan (medoid) yang berfungsi sebagai pusat kelompok pada semua cluster, sedangkan K-Means memakai angka ratarata (mean) sebagai pusat kelompok atau cluster[14] [15] Algoritma $K$-Medoids mempunyai keunggulan dalam menanggulangi kekurangan yang ada di algoritma $K$ Means yang rentan terjadi noise dan outlier, menyebabkan data dengan nilai tinggi akan ada kemungkinan menyimpang dari pendistribusian data. Keunggulan yang lain ialah pada k-medoids nilai hasil proses clustering tidak ketergantungan terhadap keterurutan masuk dataset. Algoritma $\mathrm{K}$-Medoid memiliki langkah-langkah seperti berikut:

- Inisialisasi titik cluster sejumlah k (jumlah cluster)

- Distribusikan semua data (objek) ke cluster dengan nilai jarak yang paling dekat memakai persamaan jarak Euclidean Distance :

$$
d(x i, \mu j)=\sqrt{\sum_{i=1}^{\mathrm{n}}(x i-\mu j)^{2}}
$$

Dimana: $\quad x i=$ data kriteria

$$
\mu \mathrm{j}=\text { centroid } \text { pada cluster } \mathrm{ke}-\mathrm{js}
$$

- Tentukan secara random objek dalam setiap cluster menjadi calon medoid yang baru.

- Menghitung jarak semua objek yang ada pada setiap cluster dengan calon medoid yang baru.

- Menghitung total simpangan (S) yaitu dengan cara menghitung nilai total jarak baru - total jaraklama. Jika $\mathrm{S}<0$, maka objek ditukar dengan data cluster agar menjadi kelompok $\mathrm{k}$ objek baru sebagai medoid.

- Mengulangi langkah 3 hingga 5 sampai belum terjadi perubahan medoid, sehingga diperoleh cluster beserta anggota setiap cluster.

\section{Produksi Perikanan Tangkap}

Produksi perikanan tangkap ialah data hasil tangkapan ikan yang dilakukan di perairan laut dan perairan umum baik yang didaratkan di pelabuhan maupun non pelabuhan [16]. Data disajikan menggunakan satuan ton dari tahun 2019-2020.

\section{METODE PENELITIAN}

Penelitian ini menggunakan algoritma k-medoids dalam sistem klasterisasi produksi perikanan tangkap Kabupaten Aceh Utara dengan alur penelitian sebagai berikut:

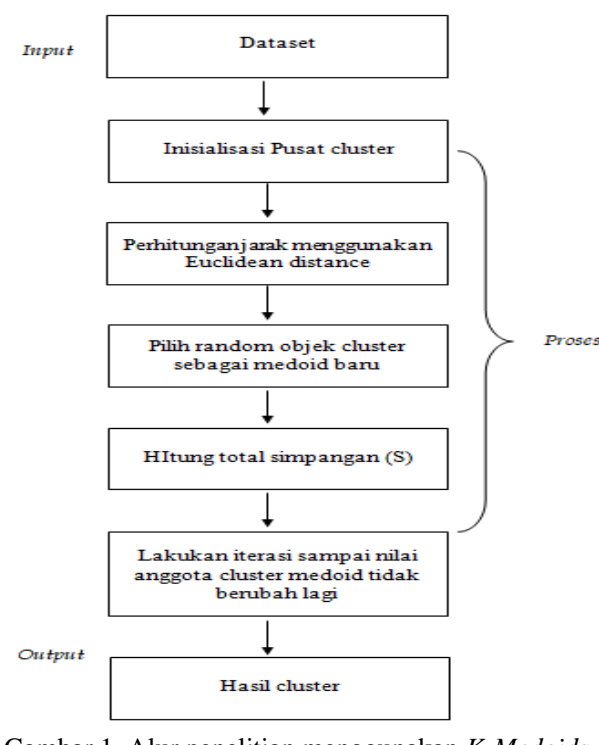

Gambar 1. Alur penelitian menggunakan K-Medoids 
Adapun tahapan dalam penelitian ini adalah:

1) Menginput dataset

2) Menginisialisasi pusat cluster

3) Menghitung jarak

4) Memilih secara random medoids baru.

5) Menghitung jarak

6) Menghitung total simpangan (S)

7) Mengulangi langkah 3 hingga 5 sampai belum terjadi perubahan medoid,

8) Output berupa cluster yang terdiri dari cluster rendah, sedang dan tinggi.

\section{IV.HASIL}

\section{A. Dataset Produksi Perikanan Tangkap}

Pada penelitian ini dataset produksi perikanan tangkap diperoleh dari Dinas Kelautan dan Perikanan Kabupaten Aceh Utara yang disajikan pada tabel 1.

TABEL I

DATASET PRODUKSI PERIKANAN TANGKAP TAHUN 2019

\begin{tabular}{|c|c|c|c|c|c|c|c|c|c|}
\hline $\begin{array}{l}\mathbf{N} \\
\mathbf{0}\end{array}$ & $\begin{array}{l}\text { Jenis } \\
\text { Ikan }\end{array}$ & $\begin{array}{l}X \\
1\end{array}$ & $\begin{array}{l}X \\
2\end{array}$ & $\begin{array}{c}X \\
3\end{array}$ & $\begin{array}{l}X \\
4\end{array}$ & $\begin{array}{l}X \\
5\end{array}$ & $\begin{array}{c}X \\
6\end{array}$ & $\begin{array}{l}X \\
7\end{array}$ & $\begin{array}{l}X \\
8\end{array}$ \\
\hline 1 & $\begin{array}{c}\text { Albak } \\
\text { ora }\end{array}$ & 4,1 & 7,6 & $\begin{array}{c}12 \\
8\end{array}$ & $\begin{array}{c}15 \\
3\end{array}$ & 6,6 & 4,3 & 5,4 & $\begin{array}{l}5, \\
5\end{array}$ \\
\hline 2 & $\begin{array}{l}\text { Alu- } \\
\text { Alu }\end{array}$ & $\begin{array}{c}12, \\
4\end{array}$ & 4,0 & $\begin{array}{c}23, \\
9\end{array}$ & $\begin{array}{c}20, \\
8\end{array}$ & $\begin{array}{c}10, \\
2\end{array}$ & 4,3 & 6,1 & $\begin{array}{l}5, \\
2\end{array}$ \\
\hline 3 & $\begin{array}{c}\text { Banya } \\
\mathrm{r}\end{array}$ & $\begin{array}{c}11, \\
0\end{array}$ & $\begin{array}{c}18, \\
0\end{array}$ & $\begin{array}{c}54, \\
4\end{array}$ & $\begin{array}{c}17, \\
0\end{array}$ & $\begin{array}{c}28, \\
2\end{array}$ & 6,9 & $\begin{array}{c}28, \\
2\end{array}$ & $\begin{array}{l}11 \\
, 9\end{array}$ \\
\hline 4 & $\begin{array}{l}\text { Bawal } \\
\text { Hitam }\end{array}$ & $\begin{array}{c}15, \\
7\end{array}$ & 6,2 & $\begin{array}{c}55, \\
2\end{array}$ & 9,8 & $\begin{array}{c}23, \\
2\end{array}$ & $\begin{array}{c}22, \\
7\end{array}$ & 9,7 & $\begin{array}{l}2, \\
9\end{array}$ \\
\hline 5 & $\begin{array}{l}\text { Bawal } \\
\text { Putih }\end{array}$ & $\begin{array}{c}24, \\
7\end{array}$ & 2,8 & $\begin{array}{c}87, \\
1\end{array}$ & $\begin{array}{c}20, \\
3\end{array}$ & $\begin{array}{c}30, \\
1\end{array}$ & $\begin{array}{c}16, \\
1\end{array}$ & 6,5 & $\begin{array}{l}4, \\
0\end{array}$ \\
\hline . & . & . & . & . & . & . & . & . & . \\
\hline . & . & . & . & . & . & . & . & . & . \\
\hline . & . & . & . & . & . & . & . & . & . \\
\hline 73 & $\begin{array}{l}\text { Tongk } \\
\text { ol Krai }\end{array}$ & $\begin{array}{c}25, \\
7\end{array}$ & $\begin{array}{c}17, \\
0\end{array}$ & $\begin{array}{c}10, \\
3\end{array}$ & $\begin{array}{c}14, \\
8\end{array}$ & 6,7 & $\begin{array}{c}13, \\
6\end{array}$ & 6,3 & $\begin{array}{l}17 \\
4\end{array}$ \\
\hline 74 & $\begin{array}{l}\text { Tuna } \\
\text { Mata } \\
\text { Besar }\end{array}$ & $\begin{array}{c}37, \\
3\end{array}$ & $\begin{array}{c}11, \\
8\end{array}$ & $\begin{array}{c}57 \\
7\end{array}$ & $\begin{array}{c}11, \\
1\end{array}$ & $\begin{array}{c}21, \\
9\end{array}$ & 4,7 & 4,7 & $\begin{array}{l}13 \\
, 2\end{array}$ \\
\hline 75 & $\begin{array}{c}\text { Tuna } \\
\text { Sirip } \\
\text { Biru } \\
\text { Selata } \\
\text { n }\end{array}$ & $\begin{array}{c}24, \\
7\end{array}$ & 7,9 & $\begin{array}{c}34, \\
6\end{array}$ & 9,6 & $\begin{array}{c}18, \\
3\end{array}$ & 2,3 & 2,3 & $\begin{array}{l}8, \\
8\end{array}$ \\
\hline
\end{tabular}

Keterangan: X1 = Dewantara, X2= Lapang, X3= Muara Batu, X4=Samudra, X5= Seunudon, X6= Syamtalira Bayu, X7= Tanah Jambo Aye, X8 $=$ Tanah Pasir.

\section{B. Hasil Perhitungan K-Medoid Pengujian Ke-1}

1) Inisialisasi Pusat Klaster Iterasi 1: untuk pemilihan setiap medoids di pilih secara acak atau random. Berikut ini adalah nilai pusat klaster awal pada pengujian ke-1 yang ditampilkan pada Tabel 2.
TABEL III

INISIALISASI PUSAT CLUSTER PENGUJIAN KE-1

\begin{tabular}{|c|c|}
\hline Data Uji Ke- & $\begin{array}{c}\text { Jenis Tangkapan } \\
\text { Ikan }\end{array}$ \\
\hline 2 & Alu Alu \\
\hline 4 & Bawal Hitam \\
\hline 5 & Bawal Putih \\
\hline
\end{tabular}

2) Menghitung jarak dengan Euclidean Distance: untuk melakukan klastering pada masing-masing data yang telah di proleh langkah selanjutnya adalah menghitung persamaan jarak menggunakan metode Euclidean Distance.

Menghitung distance data pertama dengan pusat klaster pertama:

$d_{(2.1)}=\sqrt{\begin{array}{c}(12,40-4,10)^{2}+(4,00-7,60)^{2}+(23,80-12,80)^{2}+ \\ (20,80-15,25)^{2}+(10,20-6,60)^{2}+(4,30-4,30)^{2} \\ +(6,10-5,40)^{2}+(5,20-5,50)^{2}=15,79248\end{array}}$ kedua:

Menghitung distance data pertama dengan pusat klaster $d_{(4.1)=} \sqrt{\begin{array}{c}(15,70-4,10)^{2}+(6,20-7,60)^{2}+(55,20-12,80)^{2}+ \\ (9,80-15,25)^{2}+(23,20-6,60)^{2}+(22,70-4,30)^{2} \\ +(9,70-5,40)^{2}+(2,90-5,50)^{2}=51,0230585\end{array}}$

Menghitung distance data pertama dengan pusat klaster ketiga:

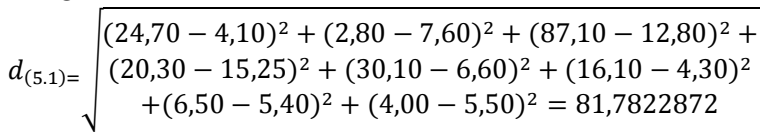

Perhitungan yang sama tetap di lakukan kepada seluruh data, Setelah di lakukan perhitungan ke seluruh data dan atribut maka akan mendapatkan jarak terdekat tiap data pada masing-masing klaster seperti Tabel 3.

TABEL IIIII

HASIL EUCLIDEAN DISTANCE ITERASI KE-1

\begin{tabular}{|c|c|c|c|c|}
\hline $\begin{array}{c}\text { Data } \\
\text { ke }\end{array}$ & C1 & C2 & C3 & $\begin{array}{c}\text { Jarak } \\
\text { Terdekat }\end{array}$ \\
\hline 1 & 15,79248 & 51,02306 & 81,78229 & 15,79248 \\
\hline 2 & 0 & 40,52444 & 68,44027 & 0 \\
\hline 3 & 44,79632 & 30,19437 & 46,04845 & 30,19437 \\
\hline 4 & 40,52444 & 0 & 36,37362 & 0 \\
\hline 5 & 68,44027 & 36,37362 & 0 & 0 \\
\hline. &. &. &. &. \\
\hline. &. &. &. &. \\
\hline. &. &. &. &. \\
\hline 73 & 28,53892 & 53,24021 & 82,85252 & 28,53892 \\
\hline 74 & 46,04769 & 31,02644 & 38,39062 & 31,02644 \\
\hline 75 & 22,43747 & 32,21847 & 57,15864 & 22,43747 \\
\hline
\end{tabular}

3) Pengelompokan Data Berdasarkan Jarak Terdekat Iterasi ke-1: langkah berkutnya setelah masingmasing data dihitung jaraknya yaitu mengelompokkan data sesuai klasternya, Kelompok klaster suatu data dihitung dari jarak terdekat dari data tehadap suatu klaster. 
TABEL IVV

KELOMPOK KLASTER DENGAN JARAK TERDEKAT

\begin{tabular}{|c|c|c|c|}
\hline $\begin{array}{c}\text { Data } \\
\text { Ke- }\end{array}$ & C1 & C2 & C3 \\
\hline 1 & $*$ & & \\
\hline 2 & $*$ & & \\
\hline 3 & & $*$ & $*$ \\
\hline 4 & & $*$ &. \\
\hline 5 & &. &. \\
\hline. &. &. & \\
\hline. &. & $*$ & \\
\hline 73 & $*$ & & \\
\hline 74 & & & \\
\hline 75 & $*$ & & \\
\hline
\end{tabular}

Berdasarkan tabel 4, data ke-1 dan ke-2 masuk dalam klaster C1, data ke-3 dan ke-4 masuk dalam klaster C2. Data ke-5 masuk ke dalam klaster C3. Data ke-73 dan data ke-75 masuk dalam klaster $\mathrm{C} 1$, sedangkan data ke-74 masuk ke dalam klaster $\mathrm{C} 2$.

4) Menentukan Nilai Medoids Baru(Non Medoids): untuk menentukan nilai medoids baru yaitu dengan cara memilih medoids baru secara acak atau random dengan ketentuan setiap medoids yang sudah terpilih maka tidak dapat di jadikan lagi sebagai medoids baru (Non Medoids). Nilai medoid baru ditampilkan pada Tabel 5.

TABEL V

INISIALISASI MEDOIDS BARU

\begin{tabular}{|c|c|}
\hline Data Uji Ke- & $\begin{array}{c}\text { Jenis Tangkapan } \\
\text { Ikan }\end{array}$ \\
\hline 1 & Albakora \\
\hline 3 & Banyar \\
\hline 6 & Belanak \\
\hline
\end{tabular}

5) Hitung Jarak pada Medoids baru: menghitung distance data pertama dengan pusat klaster pertama:

$$
d_{(1.1)}=\sqrt{\begin{array}{c}
(4,10-4,10)^{2}+(7,60-7,60)^{2}+(12,80-12,80)^{2}+ \\
(15,25-15,25)^{2}+(6,60-6,60)^{2}+(4,30-4,30)^{2} \\
+(5,40-5,40)^{2}+(5,50-5,50)^{2}=0
\end{array}}
$$

Menghitung distance data pertama dengan pusat klaster kedua:

$$
d_{(3.1)}=\sqrt{\begin{array}{c}
(11,00-4,10)^{2}+(18,00-7,60)^{2}+(54,40-12,80)^{2}+ \\
(17,00-15,25)^{2}+(28,20-6,60)^{2}+(6,90-4,30)^{2} \\
+(28,20-5,40)^{2}+(11,90-5,50)^{2}=54,0695154
\end{array}}
$$

Menghitung distance data pertama dengan pusat klaster ketiga:

$$
d_{(6.1)}=\sqrt{\begin{array}{c}
(21,90-4,10)^{2}+(15,70-7,60)^{2}+(66,80-12,80)^{2}+ \\
(12,50-15,25)^{2}+(48,40-6,60)^{2}+(15,60-4,30)^{2} \\
+(31,00-5,40)^{2}+(10,30-5,50)^{2}=76,54634217
\end{array}}
$$

Perhitungan yang sama tetap di lakukan kepada seluruh data, Setelah di lakukan perhitungan ke seluruh data dan atribut maka akan mendapatkan jarak terdekat tiap data pada masing-masing klaster seperti Tabel 6.
TABEL VI

HASIL EUCLIDEAN DISTANCE MEDOIDS BARU

\begin{tabular}{|c|c|c|c|c|}
\hline $\begin{array}{c}\text { Data } \\
\text { ke- }\end{array}$ & $\mathbf{C 1}$ & $\mathbf{C 2}$ & $\mathbf{C 3}$ & $\begin{array}{c}\text { Jarak } \\
\text { Terdeka } \\
\mathbf{t}\end{array}$ \\
\hline 1 & 0 & 54,06952 & 76,54634 & 0 \\
\hline 2 & 15,79248 & 44,79632 & 66,10136 & 15,79248 \\
\hline 3 & 54,06952 & 0 & 28,14676 & 0 \\
\hline 4 & 51,02306 & 30,19437 & 38,268 & 30,19437 \\
\hline 5 & 81,78229 & 46,04845 & 40,27729 & 40,27729 \\
\hline. &. &. &. &. \\
\hline. &. &. &. &. \\
\hline. &. &. &. &. \\
\hline 73 & 28,11214 & 56,42464 & 74,94705 & 28,11214 \\
\hline 74 & 58,71237 & 37,07155 & 43,108 & 37,07155 \\
\hline 75 & 33,06059 & 39,19298 & 54,97972 & 33,06059 \\
\hline
\end{tabular}

6) Menghitung total simpangan (S): menghitung total simpangan $(\mathrm{S})$ ialah dengan cara mencari selisih dari nilai total cost baru yang dikurangi (-) dengan nilai total cost yang lama. Dengan aturan jika $S<0$, maka tukarkan nilai objek dengan memilih nilai medoid baru. Proses nya di ulang dari langkah 4 hingga langkah 6 .

$$
\begin{aligned}
\mathrm{S} & =\text { total cost baru }- \text { total cost lama } \\
& =18321,6383-18433,7372 \\
& =-112,0988486
\end{aligned}
$$

Karena hasil total simpangan lebih kecil dari nol $\mathrm{S}<0$. Maka pengujian ini dilanjutkan dengan cara ulangi langkah sebelumnya hingga $S>0$, maka tukarkan nilai data objek dengan memilih medoids baru.

7) Menentukan Medoids Baru(Non Medoids) Iterasi ke-2: nilai medoids baru pada iterasi ke-2 ditampilkan pada Tabel 7.

TABEL VII MEDOIDS BARU

\begin{tabular}{|c|c|}
\hline Data Uji Ke- & $\begin{array}{c}\text { Jenis Tangkapan } \\
\text { Ikan }\end{array}$ \\
\hline 7 & Beloso \\
\hline 8 & Bentong \\
\hline 9 & Biji Nangka \\
\hline
\end{tabular}

8) Perhitungan jarak iterasi ke-2: menghitung distance data pertama dengan pusat klaster pertama:

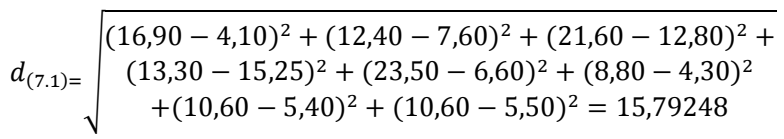

Menghitung distance data pertama dengan pusat klaster kedua:

$$
d_{(8.1)}=\sqrt{\begin{array}{c}
(4,20-4,10)^{2}+(4,80-7,60)^{2}+(7,50-12,80)^{2}+ \\
(6,50-15,25)^{2}+(2,40-6,60)^{2}+(9,50-4,30)^{2} \\
+(2,10-5,40)^{2}+(2,50-5,50)^{2}=51,0230585
\end{array}}
$$

Menghitung distance data pertama dengan pusat claster ketiga:

$$
d_{(9.1)}=\sqrt{\begin{array}{c}
(4,60-4,10)^{2}+(11,80-7,60)^{2}+(32,90-12,80)^{2}+ \\
(13,90-15,25)^{2}+(18,80-6,60)^{2}+(8,80-4,30)^{2} \\
+(13,00-5,40)^{2}+(10,40-5,50)^{2}=81,7822872
\end{array}}
$$


Pada Tabel 8 berikut ditampilkan hasil euclidean distance pada iterasi ke-2.

TABEL VIII

HASIL EUCLIDEAN DISTANCE PADA ITERASI KE-2

\begin{tabular}{|c|c|c|c|c|}
\hline $\begin{array}{c}\text { Data } \\
\text { ke- }\end{array}$ & C1 & C2 & C3 & $\begin{array}{c}\text { Jarak } \\
\text { Terdekat }\end{array}$ \\
\hline 1 & 15,79248 & 51,02306 & 81,78229 & 15,79248 \\
\hline 2 & 0 & 40,52444 & 68,44027 & 0 \\
\hline 3 & 44,79632 & 30,19437 & 46,04845 & 30,19437 \\
\hline 4 & 40,52444 & 0 & 36,37362 & 0 \\
\hline 5 & 68,44027 & 36,37362 & 0 & 0 \\
\hline. &. &. &. &. \\
\hline. &. &. &. &. \\
\hline. &. &. &. &. \\
\hline 73 & 28,53892 & 53,24021 & 82,85252 & 28,53892 \\
\hline 74 & 46,04769 & 31,02644 & 38,39062 & 31,02644 \\
\hline 75 & 22,43747 & 32,21847 & 57,15864 & 22,43747 \\
\hline
\end{tabular}

Berdasarkan Tabel 8, nilai jarak paling dekat pada data ke-1 adalah sebesar 15,79248. Nilai jarak terdekat pada data ke-2 adalah 0. Adapun nilai jarak terdekat pada data ke-3 adalah 30, 19437. Nilai jarak terdekat pada data ke-4 dan ke-5 adalah sebesar 0 . Nilai jarak terdekat pada data ke-73 adalah senilai 28,53892.

Adapun nilai jarak terdekat pada data ke-74 adalah senilai 31,02644 sedangkan nilai jarak terdekat pada data ke-75 adalah senilai 22,43747, sedangkan nilai jarak terdekat pada data ke-75 adalah sebesar 22,43747.

9) Menghitung total simpangan $(S)$

$\mathrm{S}=$ total cost baru - total cost lama

$=18581,3365-18321,6383$

$=259,6981707$

Karena hasil total simpangan lebih besar dari nol $\mathrm{S}>0$. maka pengujian ini dihentikan pada iterasi ke-2. Hasil dari iterasi terakhir akan menjadi parameter pengklasteran. Disini penulis menentukan anggota klaster mana yang masuk kedalam anggota klaster tinggi, sedang, dan rendah berdasarkan centroidnya yaitu $\mathrm{C} 1=$ rendah, $\mathrm{C} 2=$ sedang, dan $\mathrm{C} 3=$ tinggi, maka anggota dari $\mathrm{C} 1$ adalah klaster rendah, anggota dari C2 adalah klaster sedang, dan anggota C3 adalah klaster tinggi.

Hasil klaster pada pengujian ke-1 dengan menggunakan algoritma k-medoids ditampilkan pada Tabel 9.
TABEL IX

Hasil Cluster PenguJian Ke-1 TAhun 2019

\begin{tabular}{|c|c|c|}
\hline Data ke- & Jenis Tangkapan Ikan & Hasil Cluster \\
\hline 1 & Albakora & Sedang \\
\hline 2 & Alu-Alu & Rendah \\
\hline 3 & Banyar & Tinggi \\
\hline 4 & Bawal Hitam & Tinggi \\
\hline 5 & Bawal Putih & Tinggi \\
\hline$\cdot$ & $\cdot$ & $\cdot$ \\
\hline$\cdot$ & $\cdot$ & $\cdot$ \\
\hline 73 & Tongkol Krai & Rendah \\
\hline 74 & Tuna Mata Besar & Rendah \\
\hline 75 & Tuna Sirip Biru Selatan & Rendah \\
\hline
\end{tabular}

Berdasarkan Tabel 9, hasil dari pengujian pertama diperoleh data produksi perikanan tangkap dengan jenis tangkapan ikan Albakora masuk kedalam potensi produksi klaster sedang.

Adapun jenis tangkapan ikan Alu-alu, Tongkol Krai, Tuna Mata Besar, Tuna Sirip Biru Selatan masuk kedalam cluster rendah. Jenis tangkapan ikan Banyar, Bawal Hitam dan Bawal Putih masuk kedalam klaster tinggi.

\section{Hasil Iterasi K-medoids Pengujian Tahun 2019}

Berikut adalah hasil iterasi dengan 10 kali pengujian dengan medoid awal yang berbeda-beda, ditampilkan pada Tabel 10.

TABEL $\mathrm{X}$

HASIL ITERASI 10 KALI PENGUJIAN TAHUN 2019

\begin{tabular}{|c|c|c|c|c|}
\hline Pengujian Ke- & \multicolumn{3}{|c|}{ Data Uji } & Jumlah Iterasi \\
\hline 1 & 2 & 4 & 5 & 2 \\
\hline 2 & 25 & 56 & 61 & 4 \\
\hline 3 & 3 & 45 & 70 & 2 \\
\hline 4 & 3 & 26 & 61 & 2 \\
\hline 5 & 58 & 64 & 75 & 4 \\
\hline 6 & 6 & 46 & 14 & 3 \\
\hline 7 & 51 & 45 & 75 & 2 \\
\hline 8 & 74 & 63 & 2 & 2 \\
\hline 9 & 60 & 14 & 26 & 2 \\
\hline 10 & 10 & 44 & 16 & 2 \\
\hline
\end{tabular}

Dari hasil 10 kali pengujian data tahun 2019 yang di lakukan menggunakan 3 klaster dengan data pengujian yang berbeda setiap pengujiannya, pengujian dengan hasil iterasi tertinggi adalah pada pengujian ke-2 dan ke-5 sebanyak 4 iterasi. 
Pengujian ke-6 hasil iterasinya adalah sebanyak 3 iterasi. Sedangkan iterasi paling sedikit adalah sebanyak 2 iterasi yaitu pada pengujian ke-1, ke-3, ke-4, ke-7, ke- 8 , ke9, dan ke-10. Berikut adalah grafik hasil iterasi yang pengujian tahun 2019 ditampilkan pada gambar 2 .

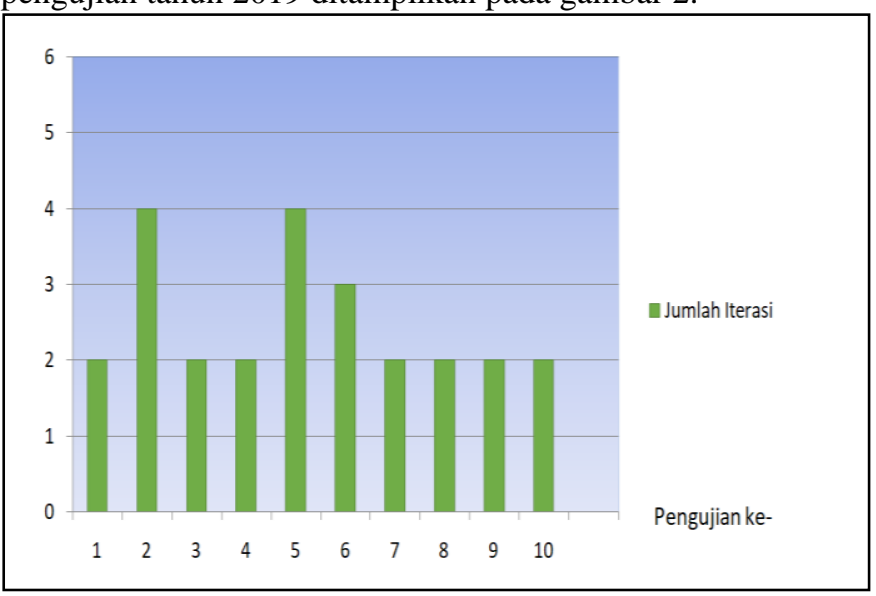

Gambar 2. Jumlah iterasi K-Medoids 10 kali pengujian tahun 2019

D. Hasil Cluster Pengujian Ke-1 Tahun 2020

Untuk pengujian pada data tahun 2020, dengan data uji ke-21, 29, dan ke-3 hasil clusternya ditampilkan pada tabel 11.

TABEL XI

Hasil Cluster PenguJian Ke-1 TAHUn 2019

\begin{tabular}{|c|c|c|}
\hline Data ke- & Jenis Tangkapan Ikan & Hasil Cluster \\
\hline 1 & Albakora & Rendah \\
\hline 2 & Alu-Alu & Sedang \\
\hline 3 & Banyar & Tinggi \\
\hline 4 & Bawal Hitam & Tinggi \\
\hline 5 & Bawal Putih & Tinggi \\
\hline$\cdot$ & $\cdot$ & $\cdot$ \\
\hline$\cdot$ & $\cdot$ & $\cdot$ \\
\hline 73 & Tongkol Krai & Rendah \\
\hline 74 & Tuna Mata Besar & Tinggi \\
\hline 75 & Tuna Sirip Biru Selatan & Sedang \\
\hline
\end{tabular}

Berdasarkan Tabel 11, hasil dari pengujian pertama diperoleh data produksi perikanan tangkap dengan jenis tangkapan ikan Albakora dan Tongkol Krai masuk kedalam potensi produksi claster rendah. Adapun jenis tangkapan ikan Alu-alu dan Tuna Sirip Biru Selatan masuk ke dalam cluster sedang. Jenis tangkapan ikan Banyar, Bawal Hitam dan Bawal Putih dan Tuna Mata Besar masuk kedalam claster tinggi.

\section{E. Hasil Iterasi K-medoids Pengujian Tahun 2020}

Berikut adalah hasil iterasi dengan 10 kali pengujian dengan medoid awal yang berbeda-beda, ditampilkan pada Tabel 12.
TABEL XII

HASIL ITERASI 10 KALI PENGUJIAN TAHUN 2020

\begin{tabular}{|c|c|c|c|c|}
\hline Pengujian Ke- & \multicolumn{3}{|c|}{ Data Uji } & Jumlah Iterasi \\
\hline 1 & 21 & 29 & 3 & 2 \\
\hline 2 & 6 & 11 & 17 & 3 \\
\hline 3 & 63 & 40 & 18 & 3 \\
\hline 4 & 15 & 1 & 24 & 3 \\
\hline 5 & 73 & 74 & 75 & 2 \\
\hline 6 & 14 & 8 & 39 & 3 \\
\hline 7 & 14 & 52 & 57 & 3 \\
\hline 8 & 7 & 43 & 9 & 2 \\
\hline 9 & 27 & 43 & 41 & 3 \\
\hline 10 & 3 & 64 & 18 & 4 \\
\hline
\end{tabular}

Berikut adalah grafik hasil iterasi pengujian data tahun 2020 yang ditampilkan pada gambar 3 .

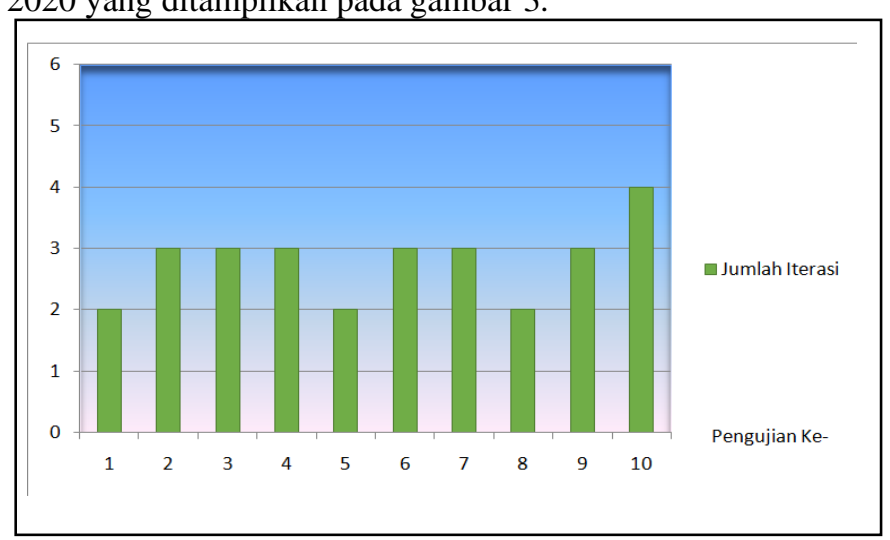

Gambar 3. Jumlah iterasi K-Medoids 10 kali pengujian tahun 2020

\section{F. Implementasi K-medoids pada Sistem}

Berikut ini ditampilkan tampilan antar muka sistem clustering produksi perikanan tangkap kabupaten aceh utara pada gambar berikut.

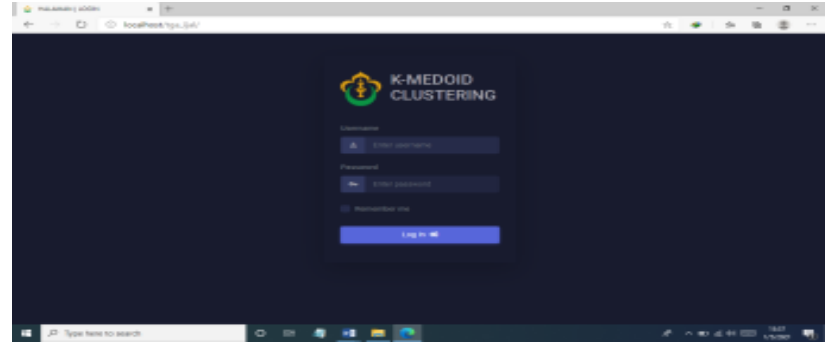

Gambar 4. Tampilan halaman login 


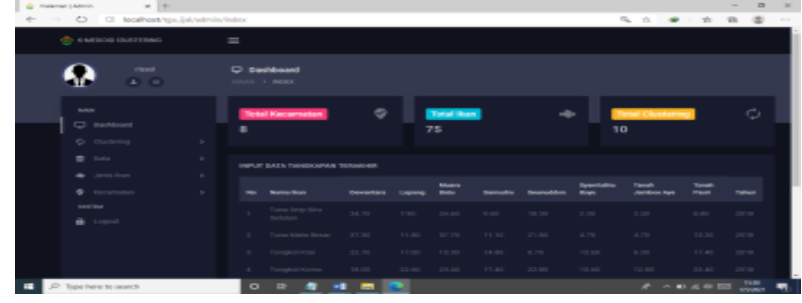

Gambar 5. Tampilan halaman dashboard

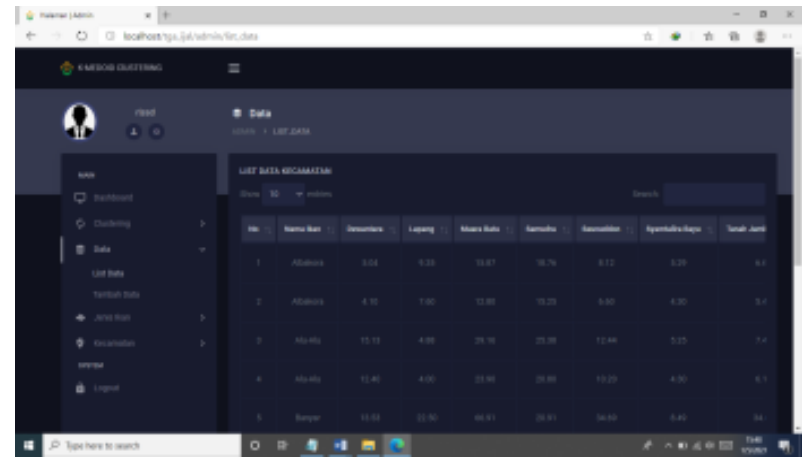

Gambar 6. Tampilan halaman kelola data

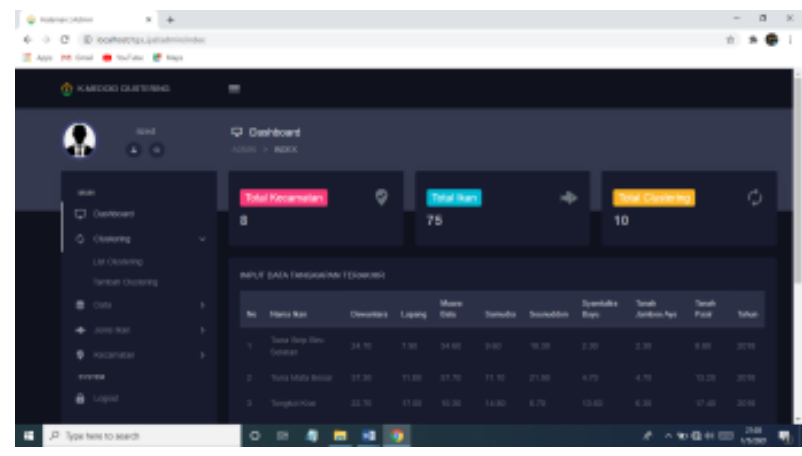

Gambar 7. Halaman clustering

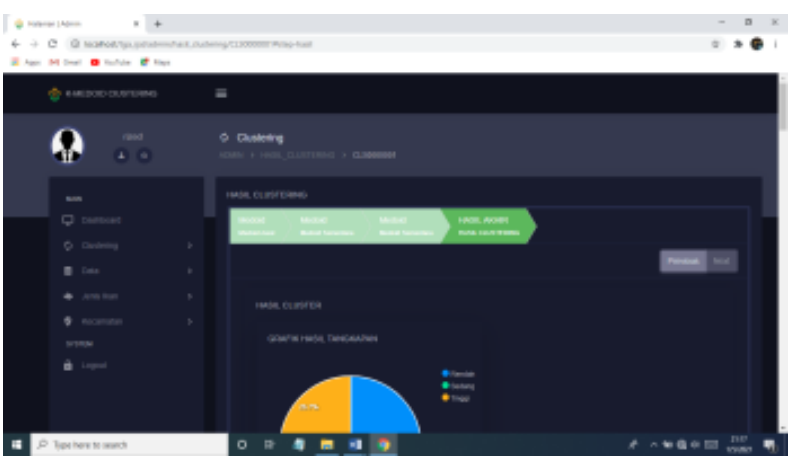

Gambar 8. Halaman hasil cluster

\section{KESIMPULAN}

Berdasarkan hasil penelitian yang telah dilakukan, penerapan algoritma $k$-medoids pada system clustering produksi perikanan tangkap kabupaten Aceh Utara berhasil mengelompokkan data menjadi tiga claster. Data produksi perikanan tangkap dengan jenis tangkapan ikan Albakora masuk kedalam potensi produksi tangkapan klaster sedang. Jenis tangkapan ikan Alu-alu, Tongkol Krai, Tuna Mata Besar, Tuna Sirip Biru Selatan masuk kedalam cluster rendah. Jenis tangkapan ikan Banyar, Bawal Hitam dan Bawal Putih masuk kedalam claster tinggi. Pengujian $k$ medoids dengan hasil iterasi tertinggi adalah pada pengujian ke-2 dan ke-5 sebanyak 4 iterasi. Pengujian ke-6 hasil iterasinya adalah sebanyak 3 iterasi. Sedangkan iterasi paling sedikit adalah sebanyak 2 iterasi yaitu pada pengujian ke-1, ke-3, ke-4, ke-7, ke-8, ke-9, dan ke-10 dengan nilai rata-rata iterasi pengujian keseluruhan adalah 2,5. Hasil cluster yang terbentuk dapat memberikan informasi kepada instansi terkait dalam mengambil kebijakan untuk menambah nilai produksi tangkapan ikan di Kabupaten Aceh Utara.

\section{REFERENSI}

[1] L. Yang, A. Shami. "On hyperparameter optimization of machine learning algorithms: Theory and practice." Neurocomputing, 2020, 415: 295-316.

[2] R. K. Dinata, S. Safwandi, N. Hasdyna, "Analisis K-Mean Clustering pada Data Sepeda Motor." INFORMAL: Informatics Journal 5.1 2020: 10-17.

[3] S. Retno. "Peningkatan Akurasi Algoritma K-Means dengan Clustering Purity Sebagai Titik Pusat Cluster Awal (Centroid)”. repositori.usu.ac.id 2019.

[4] N. Hasdyna, B. Sianipar, E. M. ZAMZAMI, "Improving The Performance of K-Nearest Neighbor Algorithm by Reducing The Attributes of Dataset Using Gain Ratio." In: Journal of Physics: Conference Series. IOP Publishing, 2020. p. 012090

[5] R. K. Dinata, F. Fajriana, Z. Zulfa, N. Hasdyna. "Klasifikas Sekolah Menengah Pertama/Sederajat Wilayah Bireuen Menggunakan Algoritma K-Nearest Neighbors Berbasis Web." CESS (Journal of Computer Engineering, System and Science), 2020, 5.1: 33-37.

[6] K. P. Sinaga, M. S. Yang "Unsupervised K-means clustering algorithm.” IEEE Access, 2020, 8: 80716-80727.

[7] N. Hasdyna, R. K. Dinata . "Analisis Matthew Correlation Coefficient pada K-Nearest Neighbor dalam Klasifikasi Ikan Hias". INFORMAL: Informatics Journal, 2020, 5.2: 57-64.

[8] R. Megawanto, A. Fauzi, L. Adrianto. "Varibel-Variabel yang Berperan Penting dalam Sistem Perikanan Tangkap Nasional." Jurnal Ilmu dan Teknologi Kelautan Tropis, 2020, 12.2: 519-542.

[9] I. Gunawan, G. Anggraeni, E.S. Rini, Y. M. Putri. "Klasterisas provinsi di Indonesia berbasis perkembangan kasus Covid-19 menggunakan metode K-Medoids." SENATIK, 2020, 301-306.

[10] J. Verbraeken, M. Wolting, J. Katzy. "A survey on distributed machine learning. ” ACM Computing Surveys (CSUR), 2020, 53.2 1-33.

[11] R. K. Dinata, H. Novriando, N. Hasdyna, S. Retno. "Reduksi Atribut Menggunakan Information Gain untuk Optimasi Cluster Algoritma K-Means.” J. Edukasi dan Penelit. Inform, 2020, 6.1: 48-53.

[12] W. Purba. "Analisis Cluster Provinsi Indonesia Berdasarkan Produksi Bahan Pangan Menggunakan Algoritma K-Means." Jurnal Sains dan Teknologi, 2020, 1.2: 5-11.

[13] T. Rizqiyah, I. Rosyida. "Analisis Cluster Tingkat Kualitas Udara Ambien Jalan Raya di Jawa Tengah Tahun 2018.” In: PRISMA, Prosiding Seminar Nasional Matematika. 2021. p. 560-564

[14] F. S. Sam, S. Syaripuddin. "Analisis Cluster Pada Produk Mie Instan Berdasarkan Komposisi Yang Terkandung Dengan Menggunakan Metode Ward." Jurnal Eksponensial, 2021, 12.1: 5358.

[15] S. W. Hadi, M. F. Julianto, S. Rahmatullah. "Analisa Cluster Aplikasi Pada App Store Dengan Menggunakan Metode KMeans". Bianglala Informatika, 2020, 8.2: 86-90.

[16] A. Susanto, A. Hamzah, R. Irnawati. "Peran Sektor Perikanan Tangkap dalam Mendukung Ketahanan Pangan Perikanan di Provinsi Banten." Leuit (Journal of Local Food Security), 2020, 1.1: 9-17. 